\title{
HPV16 variant lineage, clinical stage, and survival in women with invasive cervical cancer
}

\author{
Rosemary E Zuna ${ }^{1 *}$, Erin Tuller ${ }^{2,4}$, Nicolas Wentzensen ${ }^{3}$, Cara Mathews ${ }^{2}$, Richard A Allen ${ }^{1}$, Rebecca Shanesmith ${ }^{1,5}$,
} S Terence Dunn', Michael A Gold ${ }^{1,2,6}$, Sophia S Wang ${ }^{3,7}$, Joan Walker ${ }^{2}$ and Mark Schiffman ${ }^{3}$

\begin{abstract}
Background: HPV16 variants are associated with different risks for development of CIN3 and invasive cancer, although all are carcinogenic. The relationship of HPV 16 variants to cancer survival has not been studied.

Methods: 155 HPV16-positive cervical cancers were categorized according to European and non-European variant patterns by DNA sequencing of the E6 open reading frame. Clinico-pathologic parameters and clinical outcome were collected by chart review and death registry data.

Results: Of the 155 women (mean age 44.7 years; median follow-up 26.7 months), 85.2\% harbored European variants while $14.8 \%$ had non-European sequences. HPV16 variants differed by histologic cell type $(p=0.03)$ and stage (1 vs. 2+; $p=0.03$ ). Overall, 107 women (68.0\%) were alive with no evidence of cancer, 42 (27.1\%) died from cervical cancer, 2 (1.3\%) were alive with cervical cancer, and 4 (2.6\%) died of other causes. Death due to cervical cancer was associated with European variant status $(p<0.01)$. While $31 \%$ of women harboring tumors with European variants died from cervical cancer during follow-up, only 1 of 23 (4.4\%) non-European cases died of cancer. The better survival for non-European cases was partly mediated by lower stage at diagnosis.
\end{abstract}

Conclusions: Overall, invasive cervical cancers with non-European variants showed a less aggressive behavior than those with European variants. These findings should be replicated in a population with more non-European cases.

Keywords: cervical neoplasms, human papillomavirus 16, HPV16 variants

\section{Background}

While the association of HPV genotypes and cervical carcinoma is well established, the reasons that only a subset of lesions associated with high-risk genotypes progress to invasive cancer remain elusive. Influential variables likely include individual host factors, viral differences or combinations of both.

One variable that could contribute to differences in biological behavior of HPV- associated lesions is that of HPV DNA sequence variation. HPV16, which is the most prevalent HPV genotype and is associated with approximately half of cervical cancers worldwide [1], has well-documented DNA sequence variants. HPV variants are defined as isolates with primary DNA sequence differences that total no more than $2 \%$ of the $L 1$ open

\footnotetext{
* Correspondence: rosemary-zuna@ouhsc.edu

'Department of Pathology, University of Oklahoma Health Sciences Center,

940 SL Young Blvd, Oklahoma City, Oklahoma, 73104-5042, USA

Full list of author information is available at the end of the article
}

reading frame $(\mathrm{ORF})$ of the prototype sequence [2]. The sequence variations of the HPV16 E6 ORF have been found to correctly classify the HPV16-variants [3]. Two major categories of HPV16 variants have been defined: European (E) and Non-European (NE) patterns that appear to have evolved principally on a geographic basis [4]. A number of studies have suggested that HPV16 variants differ in risk for progression to high grade intraepithelial lesions [5-7] and in their association with the development of cancer [8-12]. Overall, the 16-NE variants have shown an increased risk for progression to CIN2 or greater when compared with 16-E.

We have previously reported the patterns of HPV16 variants in the spectrum of cervical lesions in our population [11]. While our study confirmed the increased risk for progression to carcinoma associated with 16-NE variants, 16-E patterns were found in the majority of HPV16 lesions, including cancers. We attributed this to the dominance of the 16 -E patterns in our population
C Biomed Central

(C) 2011 Zuna et al; licensee BioMed Central Ltd. This is an Open Access article distributed under the terms of the Creative Commons Attribution License (http://creativecommons.org/licenses/by/2.0), which permits unrestricted use, distribution, and reproduction in any medium, provided the original work is properly cited. 
and to the fact that all major variant categories can be found in cancers.

In this follow-up study, we address the question of whether HPV16 variant status influences clinical patterns and/or prognosis in fully evolved cervical cancers. We performed a cross-sectional analysis of the clinicopathologic characteristics of an unselected, prospectively accumulated population of women with HPV16-positive invasive cervical cancer from the central United States. The tumors were categorized according to histologic cell type and HPV16 variant category. We also correlated the clinico-pathologic characteristics and clinical follow-up with HPV16-variant category in an effort to evaluate the possible association of the HPV16 variants with clinical behavior in cervical cancers.

A similar analysis was performed for the largest subpopulation, i.e., HPV16-positive squamous cell cancers harboring European variants, in an effort to identify differing patterns of biologic behavior within sub-lineages of this dominant category.

\section{Results}

\section{Patient Demographics}

The population of 155 women with HPV16- associated cancers had a mean age of 44.7 years \pm 1.0 (SEM), ranging from 20-76 years. Median follow-up was $26.7 \pm$ 24.5 months (mean $=31.5 \pm 2.0$ months). Overall, 107 women $(68.0 \%)$ were alive with no evidence of cancer, 42 (27.1\%) died from cervical cancer, 2 (1.3\%) were alive with cervical cancer, and $4(2.6 \%)$ had died of other causes. Of these cases, 132 (85.2\%) harbored 16-E variants while $23(14.8 \%)$ had $16-\mathrm{NE}$ patterns $(\mathrm{AA}=17$ cancers, NA- $1=3$, AF1 and AF2 $=3$ ). The patient characteristics for this population, sorted according to variant status, are summarized in Table 1 .

\section{Clinico-pathologic variables}

Of 149 women with definite clinical outcome, the overwhelming majority, $91.3 \%$, were diagnosed with SCC. 16-E variants were identified in 119 (87.5\%) SCC lesions. These accounted for $93.7 \%$ of all $16-\mathrm{E}$ variant cases in this population. Although SCC cancers harboring 16-E variants dominated in this population, and $16-\mathrm{E}$ cases were more frequent in all other histologic categories as well, the percentage of 16-NE variants ranged from $44.4 \%$ (4 of 9) of CAC compared with 25\% (1 of 4) for ASC and 12.5\% (17 of 136) for SCC. The distribution of individual 16-NE variant categories for histologic cell type is as follows: $\mathrm{AA}=12 \mathrm{SCC}$ and 4. $\mathrm{CAC}$; NA-1 = 3 SCC; AF1 = $1 \mathrm{SCC}$ and AF2 $=1$ SCC and 1 ASC. Despite the disparity in case numbers, the differences in the distribution of HPV16-variants among the histologic cell types were statistically significant $(\mathrm{p}=0.03)$.
There was no significant difference in the distribution of HPV16 variants according to tumor size, depth of invasion, vascular space invasion, lymph node involvement, parametrial involvement, or status of surgical margins. Similarly, none of the clinical parameters showed a significant difference associated with 16-variant status including race/ethnicity, age group, FIGO stage and number of pregnancies.

Although significant differences were not identified between the 16-E and 16-NE variant groups for the above prognostic variables affecting survival in cervical cancer patients, there were interesting trends among 16NE cases for some parameters that may reveal significance in a larger study with a larger population of 16NE cases. These variables include younger age, early stage at presentation, three or fewer pregnancies, race/ ethnicity other than white, depth of stromal invasion greater than $5 \mathrm{~mm}$, and the presence of lymphovascular space invasion for 16-NE patients. While not statistically significant $\left(\mathrm{p}_{\text {trend }}=0.13\right.$ ), the modal peak for $16-\mathrm{NE}$ cases was the 31-40 age group (mean $=41.4 \pm 2.6$ years; median 38 years) compared with the 41-50 group for the $16-\mathrm{E}$ cases $($ mean $=45.3 \pm 1.0$; median 45 years). Figure 1 illustrates that the majority of women with 16 NE lesions presented at stage IB1 while those with 16-E lesions presented at a more variable stage $\left(p_{\text {trend }}=0.02\right)$.

Because of the uneven distribution of cases in this study, a second analysis was performed that was restricted to the 123 cases of SCC associated with European variants. This population had a mean age of 45.9 years $\pm 1.1(\mathrm{SEM})$, ranging from 20 to 76 years of age. Median follow-up was 28 months \pm 22.4 (mean $33.0 \pm 2.0)$. This population was divided into three categories as follows based on subgroups of European variants: European prototype $(16-\mathrm{EP})(\mathrm{N}=53)$, European variants with a small number of nucleotide changes compared to prototype $(16-\mathrm{EV})(\mathrm{N}=21)$, and those European variants harboring the $350 \mathrm{~T}>\mathrm{G}$ nucleotide change $(\mathrm{N}=49)$.

The 16-EV category has been previously described [11] and is similar to the European prototype with the addition of one or more single nucleotide changes. In this report, we subdivided the 16-EV category into two groups based on the presence or absence of the common $350 \mathrm{~T}>\mathrm{G}$ nucleotide change. In the first, termed 16EV here, the nucleotide pattern differed from prototype by one nucleotide alteration. The location of the nucleotide change was variable and only the $178 \mathrm{~T}>\mathrm{G}$ (sometimes termed the As variant) alteration ( $n=4)$ was found in more than one case. The second pattern (16EV-G) was defined by the presence of the European 350 $\mathrm{T}>\mathrm{G}$ alteration as a single nucleotide change or with a small number of additional single nucleotide changes [11]. For example, three cases in this group showed a 
Table 1 Clinicopathologic Features of 149 Cervical Cancer Cases

\begin{tabular}{|c|c|c|c|c|c|}
\hline TRAIT & CATEGORY & $\begin{array}{l}\text { EUROPEAN }\left(\%^{1}\right) \\
\mathrm{n}=127\end{array}$ & $\begin{array}{l}\text { NON EUROPEAN }\left(\%^{1}\right) \\
\mathrm{n}=\mathbf{2 2}\end{array}$ & TOTAL $\left(\%^{2}\right)$ & $\begin{array}{l}\text { P-VALUE }^{3} \\
n=149\end{array}$ \\
\hline & Squamous Carcinoma & 119 (87.5) & $17(12.5)$ & $136(91.3)$ & \\
\hline \multirow[t]{2}{*}{ CELL TYPE } & Adenocarcinoma & $5(55.6)$ & $4(44.4)$ & $9(6.0)$ & 0.03 \\
\hline & Adenosquamous Ca & $3(75.0)$ & $1(25.0)$ & $4(2.7)$ & \\
\hline AGE GROUP & $20-40$ & $46(78.0)$ & $13(22.0)$ & 59 (39.6) & \\
\hline \multirow[t]{3}{*}{ (YEARS) } & $41-50$ & $46(92.0)$ & $4(8.0)$ & $50(33.6)$ & 0.13 \\
\hline & $51-72$ & $35(87.5)$ & $5(12.5)$ & $40(26.8)$ & \\
\hline & White & $102(88.7)$ & $13(11.3)$ & $115(77.7)$ & \\
\hline \multirow[t]{7}{*}{ RACE } & Black & $4(80.0)$ & $1(20.0)$ & $5(3.4)$ & 0.11 \\
\hline & Hispanic & $7(63.6)$ & $4(36.4)$ & $11(7.4)$ & \\
\hline & Native American & $10(71.4)$ & $4(28.6)$ & $14(9.5)$ & \\
\hline & Asian & $2(100)$ & 0 & $2(1.4)$ & \\
\hline & Other & $1(100)$ & 0 & $1(0.7)$ & \\
\hline & Unknown & $1-$ & - & $1-$ & \\
\hline & $1 \mathrm{~A}$ & $14(87.5)$ & $2(12.5)$ & $16(11.1)$ & \\
\hline \multirow[t]{7}{*}{ STAGE (FIGO) } & 1B1 & $42(75.0)$ & $14(25.0)$ & $56(38.9)$ & 0.16 \\
\hline & 1B2 & $16(88.9)$ & $2(11.1)$ & $18(12.5)$ & \\
\hline & 2 & $22(91.7)$ & $2(8.3)$ & $24(16.7)$ & \\
\hline & 3 & $18(94.7)$ & $1(5.3)$ & 19 (13.2) & \\
\hline & 4 & $11(8.9)$ & 0 & $11(7.6)$ & \\
\hline & Recurrent/Unstaged & $4-$ & $1-$ & $5-$ & \\
\hline & 0 & $6(85.7)$ & $1(14.3)$ & $7(4.9)$ & \\
\hline \multirow[t]{3}{*}{ GRAVIDITY } & $1-3$ & $73(82.0)$ & $16(18.0)$ & 89 (61.8) & 0.13 \\
\hline & $>3$ & $45(93.8)$ & $3(6.3)$ & $48(33.3)$ & \\
\hline & $N^{4}$ & $3-$ & $2-$ & $5-$ & \\
\hline \multirow[t]{3}{*}{ PARAMETRIA $^{5}$} & Negative & $53(77.9)$ & $15(22.1)$ & $68(60.7)$ & 0.12 \\
\hline & Positive & $40(90.9)$ & $4(9.1)$ & $44(39.3)$ & \\
\hline & ND & $34-$ & $3-$ & $37-$ & \\
\hline \multicolumn{6}{|l|}{ Table 1 (cont'd) } \\
\hline & $<1$ & $16(84.2)$ & $3(15.8)$ & 19 (14.6) & \\
\hline \multirow[t]{4}{*}{ TUMOR SIZE } & $1-4$ & $42(76.4)$ & $13(23.6)$ & $55(42.3)$ & 0.1 \\
\hline & $>4$ & $51(91.1)$ & $5(8.9)$ & $56(43.1)$ & \\
\hline & ND & $18-$ & $1-$ & $19-$ & \\
\hline & $<3$ & $15(93.8)$ & $1(6.3)$ & 16 (19.3) & \\
\hline INVASION DEPTH ${ }^{6}$ & $3.1-5.0$ & $10(83.3)$ & $2(16.7)$ & $12(14.5)$ & 0.21 \\
\hline \multirow[t]{3}{*}{$(\mathrm{mm})$} & $>5$ & $40(72.7)$ & $15(27.3)$ & $55(66.3)$ & \\
\hline & ND & $62-$ & $4-$ & $66-$ & \\
\hline & Positive & $40(74.1)$ & $14(25.9)$ & $54(62.1)$ & \\
\hline \multirow[t]{2}{*}{$\operatorname{VSI}{ }^{6}$} & Negative & 29 (87.9) & $4(12.1)$ & $33(37.9)$ & 0.17 \\
\hline & ND & $58-$ & $4-$ & $62-$ & \\
\hline
\end{tabular}


Table 1 Clinicopathologic Features of 149 Cervical Cancer Cases (Continued)

\begin{tabular}{|c|c|c|c|c|c|}
\hline RESECTION & Positive & 11 (91.7) & $1(8.3)$ & $12(14.6)$ & \\
\hline \multirow[t]{2}{*}{ MARGINS $^{6}$} & Negative & $53(75.7)$ & $17(24.3)$ & $70(85.4)$ & 0.29 \\
\hline & ND & $63-$ & $4-$ & $67-$ & \\
\hline \multirow[t]{4}{*}{ LYMPH NODES $^{7}$} & Negative & $48(85.7)$ & $8(14.3)$ & $56(50.4)$ & \\
\hline & Positive & $44(80.0)$ & $11(20.0)$ & 55 (49.6) & 0.46 \\
\hline & ND & $35-$ & $3-$ & $38-$ & \\
\hline & NED & $86(80.4)$ & 21 (19.6) & $107(71.8)$ & \\
\hline STATUS ${ }^{8}$ & DOD & 41 (97.6) & $1(2.4)$ & $42(28.2)$ & 0.008 \\
\hline
\end{tabular}

${ }^{1}$ : Percentage calculated across.

${ }^{2}$ : Percentage calculated down.

3. Fisher's Exact Test

4. ND: No data available

5: Parametrial assessment and tumor size were determined by pathologic analysis of a radical hysterectomy or as part of a clinical staging procedure.

${ }^{6}$ : Depth of invasion, margin status and status of vascular space invasion were available only for women with early stage tumors who had a conization or hysterectomy.

7: Lymph node dissections were routinely performed as part of radical hysterectomy. It is not standard for higher stage women although cervical biopsy with lymph node dissection was performed for some higher stage women.

8: Status: NED = No evidence of cervical cancer at last follow-up; DOD = Dead of cervical cancer

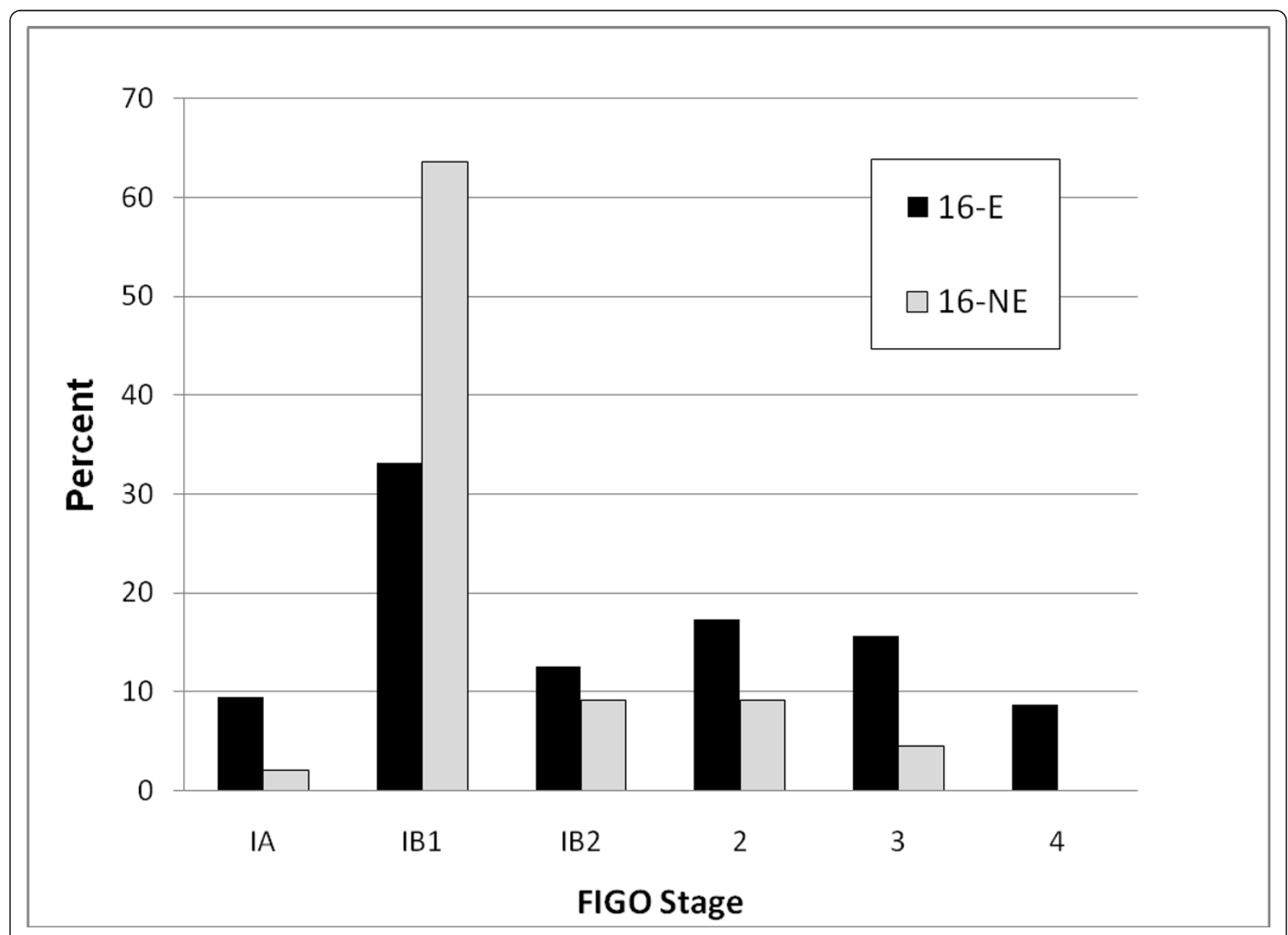

Figure 1 Distribution of FIGO stage for women presenting with cervical carcinoma according to 16 -variant status 
$131 \mathrm{~A}>\mathrm{G}$ change in addition to $350 \mathrm{~T}>\mathrm{G}$. Because of the frequency of the $350 \mathrm{~T}>\mathrm{G}$ pattern, this group of $16-\mathrm{EV}$ tumors was analysed separately in this study in an effort to clarify the clinical significance of this change. The 16EV-G category specifically excludes the $16-\mathrm{NE}$ variants that contain this same nucleotide 350 alteration. The clinico-pathologic characteristics of this population are shown in Table 2.

Cross-sectional analysis restricted to the subgroup of 123 women with SCC harboring European variants failed to demonstrate significant differences among the various clinical and pathologic traits for the different variant categories (Table 2). The 16-EP and 16-EV-G categories had similar characteristics. The 16-EV group was somewhat divergent but the numbers were small and the differences not significant. A comparison of 16EV-G cases relative to all other 16-E SCC also showed no significant differences (data not shown).

\section{Clinical Follow-up}

After a median follow-up of 29.1 months \pm 23.3 , death due to cervical cancer was highly associated with $16-\mathrm{E}$ variant status $(\mathrm{p}<0.01)$. While $31 \%(41 / 127)$ of women harboring tumors with $16-\mathrm{E}$ variants died from cervical cancer, only 1 of 23 (4.4\%) 16-NE cases died of cervical cancer. There were no differences in follow-up status or total follow-up time within the subgroups of 16-E squamous cancers.

We attempted to explain the survival differences by adjustment (by stratification or restriction) for possible

Table 2 Clinicopathologic Features of 119 HPV16-Positive Squamous Cell Carcinoma Cases with European Variants

\begin{tabular}{|c|c|c|c|c|c|c|}
\hline TRAIT & CATEGORY & $\begin{array}{c}\text { 16-EP }\left({ }^{1}\right) \\
\mathrm{n}=52\end{array}$ & $\begin{array}{c}\text { 16-EV }\left(\%^{1}\right) \\
n=20\end{array}$ & $\begin{array}{c}\text { 16-EV-G }\left(\%^{1}\right) \\
n=47\end{array}$ & $\begin{array}{c}\text { Total }\left(\%^{2}\right) \\
\mathrm{n}=119\end{array}$ & P-VALUE $^{3}$ \\
\hline & Non-keratinizing & $26(41.9)$ & $12(19.4)$ & $24(38.7)$ & $62(57.4)$ & \\
\hline \multirow[t]{2}{*}{ CELL TYPE } & Keratinizing & $21(45.7)$ & $5(10.9)$ & $20(43.5)$ & $46(42.6)$ & 0.53 \\
\hline & Squamous, NOS $^{4}$ & $5-$ & $3-$ & $3-$ & $11-$ & \\
\hline \multirow[t]{3}{*}{ AGE GROUP } & $20-40$ & $15(37.5)$ & $5(12.5)$ & $20(50.0)$ & 40 (33.6) & \\
\hline & $41-50$ & $20(45.5)$ & $11(25.0)$ & $13(29.5)$ & $44(37.0)$ & 0.26 \\
\hline & $51-72$ & $17(48.6)$ & $4(11.4)$ & $14(40.0)$ & $35(29.4)$ & \\
\hline \multirow[t]{8}{*}{ RACE } & White & $44(45.8$ & 15 (15.6) & 35 (38.5) & $94(76.1)$ & \\
\hline & Black & $2(50.0)$ & $2(50.0)$ & 0 & $4(3.4)$ & 0.07 \\
\hline & Hispanic & $2(28.6)$ & 0 & $5(71.4)$ & $7(5.9)$ & \\
\hline & Native American & $3(30.0)$ & $1(10.0)$ & $6(60.0)$ & $10(8.5)$ & \\
\hline & Asian & $1(50.0)$ & $1(50.0)$ & 0 & $2(1.7)$ & \\
\hline & Other & $0-$ & $1(100)$ & 0 & $1(0.8)$ & \\
\hline & $N D^{5}$ & $0-$ & $0-$ & $1-$ & $1-$ & \\
\hline & $1 \mathrm{~A}$ & $6(42.9)$ & $2(14.3)$ & $6(42.9)$ & $14(12.2)$ & \\
\hline \multirow[t]{7}{*}{ STAGE (FIGO) } & 1B1 & $16(44.4)$ & $8(22.2)$ & $12(33.3)$ & $36(31.3)$ & 0.75 \\
\hline & 1B2 & $4(28.6)$ & $3(21.4)$ & $7(50.0)$ & $14(12.2)$ & \\
\hline & 2 & $10(45.5)$ & $1(4.5)$ & $11(50.0)$ & $22(19.1)$ & \\
\hline & 3 & $9(50.0)$ & $3(16.7)$ & $6(33.3)$ & $18(15.6)$ & \\
\hline & 4 & $5(45.5)$ & $3(27.3)$ & $3(27.3)$ & $11(9.6)$ & \\
\hline & Recurrent/Unstaged & $2-$ & $0-$ & $2-$ & $4-$ & \\
\hline & 0 & $4(80.0)$ & $0-$ & $1(20.0$ & $5(4.3)$ & \\
\hline \multirow[t]{3}{*}{ GRAVIDITY } & $1-3$ & $24(35.8)$ & $11(16.4)$ & $32(47.8)$ & $67(57.8)$ & 0.18 \\
\hline & $>3$ & $22(50.0)$ & $9(20.5)$ & $13(29.5)$ & 44 (37.9) & \\
\hline & $N D^{5}$ & $2-$ & $0-$ & $1-$ & $3-$ & \\
\hline \multirow[t]{3}{*}{ PARAMETRIA $^{6}$} & Negative & $20(43.5)$ & $8(17.4)$ & $18(39.1)$ & $46(53.5)$ & \\
\hline & Positive & $19(47.5)$ & $6(15.0)$ & $15(37.5)$ & $40(46.6)$ & 0.92 \\
\hline & ND & $13-$ & $6-$ & $14-$ & $33-$ & \\
\hline
\end{tabular}


Table 2 Clinicopathologic Features of 119 HPV16-Positive Squamous Cell Carcinoma Cases with European Variants (Continued)

\begin{tabular}{|c|c|c|c|c|c|c|}
\hline Table 2 (cont'd) & & & & & & \multirow{5}{*}{0.96} \\
\hline \multirow{4}{*}{ TUMOR SIZE $(\mathrm{cm})$} & $<1$ & $6(40.0)$ & $2(13.3)$ & $7(46.7)$ & $15(14.7)$ & \\
\hline & $1-4$ & $18(46.2)$ & $7(17.9)$ & $14(35.9)$ & $39(38.2)$ & \\
\hline & $>4$ & $21(43.8)$ & $7(14.6)$ & $20(41.7)$ & $48(47.1)$ & \\
\hline & ND & $7-$ & 4 - & $6-$ & $17-$ & \\
\hline \multirow{4}{*}{$\begin{array}{c}\text { INVASION DEPTH }{ }^{7} \\
(\mathrm{~mm})\end{array}$} & $<3$ & $3(23.1)$ & $2(15.4)$ & $8(61.5)$ & $13(22.0)$ & \multirow{4}{*}{0.24} \\
\hline & $3.1-5.0$ & $5(62.5)$ & 0 & $3(37.5)$ & $8(13.3)$ & \\
\hline & $>5$ & $19(50.0)$ & $7(18.4)$ & $12(31.6)$ & $38(64.4)$ & \\
\hline & ND & $25-$ & $11-$ & $24-$ & $60-$ & \\
\hline \multirow{3}{*}{$\mathrm{VSI}^{7}$} & Positive & $15(40.5)$ & $6(16.2)$ & $16(43.2)$ & $37(59.7)$ & \multirow{3}{*}{0.83} \\
\hline & Negative & $12(48.0)$ & $3(12.0)$ & $10(40.0)$ & $25(40.3)$ & \\
\hline & ND & $25-$ & $11-$ & $21-$ & $57-$ & \\
\hline RESECTION & Positive & $7(63.6)$ & $1(9.1)$ & $3(27.3)$ & $11(19.3)$ & \multirow{3}{*}{0.49} \\
\hline \multirow[t]{2}{*}{ MARGINS ${ }^{7}$} & Negative & $19(41.3)$ & $8(17.4)$ & $19(41.3)$ & $46(80.7)$ & \\
\hline & ND & $26-$ & $11-$ & $25-$ & $65-$ & \\
\hline \multirow{3}{*}{ LN STATUS ${ }^{8}$} & Negative & $20(47.6)$ & $4(9.5)$ & $18(42.9)$ & $42(49.4)$ & \multirow{3}{*}{0.55} \\
\hline & Positive & $18(41.9)$ & $8(18.6)$ & $17(39.5)$ & $43(50.6)$ & \\
\hline & ND & $14-$ & 8 - & $12-$ & $34-$ & \\
\hline & NED & 34 42.5) & $13(16.3)$ & $33(41.3)$ & $80(67.2)$ & \\
\hline STATUS $^{9}$ & DOD & $1846.2)$ & $7(17.9)$ & $14(35.9)$ & 39 (32.8) & 0.87 \\
\hline
\end{tabular}

${ }^{1}$ : Percentage calculated across.

2: Percentage calculated down.

3: Fisher's exact test

4: Squamous, NOS: Women with very small tumors or tiny biopsies were difficult categorize as to cell type and were not included in these analyses.

5: ND: No data available

${ }^{6}$ : Tumor size and parametrial assessment were determined by pathologic evaluation of a radical hysterectomy or as part of a clinical staging procedure.

${ }^{7}$ : Depth of invasion, margin status and status of vascular space invasion were available only for women with early stage tumors who had a conization or hysterectomy.

8: Lymph node dissections were routinely performed as part of radical hysterectomy. It is not standard for higher stage women although cervical biopsy with lymph node dissection was performed for some higher stage women.

?: Status: NED = No evidence of cervical cancer; DOD = Dead of cervical cancer

factors such as stage at diagnosis or age, which showed a relationship both to variant status and outcome. Even within Stage 1 cancers, however, for which survival was favorable, tumors with 16-E variants tended to have somewhat worse outcomes than those with 16-NE variants (data not shown).

\section{Discussion}

The rationale behind the possibility of biological differences associated with variant status is related to alterations in primary HPV DNA sequence that may alter control elements or affect the function of translated proteins that interact with the host. For example, the most common $E 6$ sequence variation from prototype described in the 16-E-variants is $350 \mathrm{~T}>\mathrm{G}$ that results in a L83V amino acid change in the E6 protein. Such amino acid changes can potentially alter tertiary structure and may influence protein function. In vitro studies of different HPV16-variants have suggested differences in biological activity [13], but an in vivo mechanism of enhanced biological activity has not been described. To date, evidence for different biological effects related to the sequence variants in patients has accumulated on an epidemiologic basis.

The increased risk for progression of 16-NE cervical lesions to high grade CIN and carcinoma has been attributed in part to reports that $16-\mathrm{NE}$ variants are associated with a higher rate of HPV16 persistence and development of high-grade intraepithelial cervical lesions $[6,7]$. In this report, we explored the question of 
whether this increased risk for progression associated with 16-NE variants also correlates with increased aggressiveness of fully evolved invasive cancers. Our data for 155 HPV16-positive cervical cancer cases followed for a median of 29.1 months does not support this hypothesis. In fact, the women with tumors harboring 16-E variants had a statistically increased risk of death due to cervical cancer. A major problem in interpreting these results, however, is the skewed pattern of our cases, with strong predominance of squamous cancers and 16-E patterns. This imbalance could mask any possible difference in the behavior associated with the 16-NE lesions. For example, 16-NE variants, particularly the AA variant, have been reported to be associated with CAC $[9,10]$ which have a more aggressive course than SCC in some reports [14,15]. In this population, however, only 14 (9.0\%) HPV16-positive cases were CAC or ASC.

Survival in cervical cancer patients is related primarily to stage at diagnosis, tumor size, depth of cervical stromal invasion, parametrial involvement, lymphovascular space invasion, and lymph node status [16]. Histologic cell type [17] as well as HPV genotype, especially HPV18 [18] have also been reported as prognostic factors.

While survival in this study was correlated with $16-\mathrm{E}$ variant status, there are clues to suggest that this may be an overly simplistic impression given the disproportionate number of cases in the two groups. In this study most of the 16-NE cancer patients presented at a young age and at an early stage (1B1). Additionally, these data showed non-significant trends in which 16-NE lesions had larger size at presentation with increased rate of vascular space invasion and lymph node metastases. It is therefore conceivable that the small number of $16-\mathrm{NE}$ lesions in this population has resulted in a non-representative distribution of cases. Similarly, it is not clear whether this pattern is representative of all 16-NE cases or if our population is simply anomalous due to small numbers of 16-NE cases. Conceivably, our young 16-NE cases represent a detection bias in which younger women with cancer were identified because of screening while the older 16-E population presented with signs and symptoms of cancer. The relatively small proportion of 16-NE cases could thus result in anomalous results. On the other hand, these results raise the possibility that 16-NE variants have a preferential role in progression to malignancy but do not differentially influence clinical behavior in fully evolved cancers. When we analyzed a subpopulation of cancer cases representing the dominant group of HPV16 European sequence patterns, we were unable to show a difference in clinical behavior based on subcategories of $16-\mathrm{E}$ variants.

\section{Conclusions}

While our earlier study showed a significant association of 16-NE variant status with progression to high grade CIN and invasive cancer in cases with a wide spectrum of cervical disease[11], we have not been able demonstrate more aggressive behavior for actual invasive carcinomas associated with these variants. These results, however, should be interpreted with caution due to the limited number of 16-NE cases in this population. A larger study with a larger population of 16-NE cases is needed to clarify these issues.

\section{Methods}

\section{Patient Population}

From 1999-2009, 319 unselected cases of primary, metastatic and recurrent invasive cervical carcinoma were prospectively entered into this study based on the collection of a liquid-based cytologic sample that was tested for HPV DNA and a histologic diagnosis of invasive cervical cancer. The population seen at our institution is variably screened for cervical cancer so that some cancer patients were identified by routine screening while others presented with clinical signs and symptoms related to cervical cancer. Included in this total were 164 cases from the SUCCEED study [19] and 85 cases that were included in previous reports [20]. These women were staged according to FIGO (International Federation of Gynecology and Obstetrics, 2000) and treated at the OU Medical Center in Oklahoma City using standard therapies of surgery, radiation, and chemotherapy as indicated by individual patient characteristics. Of the 167 HPV16-positive cancer cases, 155 were available for variant analysis. Because 80 (51.6\%) women did not undergo total hysterectomy and 40 (25.8\%) did not have a lymphadenectomy, some pathologic variables were not evaluable in all cases. Follow-up was determined by chart review and death records for the state of Oklahoma. In addition to clinico-pathologic parameters, we compared over-all follow-up taking into account clinical stage at diagnosis, race, age, and censoring due to loss-to-follow-up. Statistical analyses reported below were performed using the population of women $(\mathrm{n}=$ 149) with defined outcome (i.e., no evidence of disease or dead of cervical cancer). This study was performed with the approval of the Institutional Review Board for the University of Oklahoma Health Sciences Center.

\section{Pathologic Categorization}

All cancer diagnoses were confirmed histologically and the cell type was determined using routine hematoxylin and eosin staining supplemented by any special stains performed at the time of initial diagnosis. The tumor cell types were categorized using standard histologic 
criteria [21]. Squamous cell carcinomas (SCC) were designated as "large cell keratinizing" when at least one well-formed keratin pearl was identified [22] and "large cell non-keratinizing" when no pearls were identified. Squamous tumors that were very small or for which only small biopsies were available, were listed as "SCC, not otherwise specified".

The major histologic categories included SCC ( $\mathrm{n}=$ 141), both keratinizing and non-keratinizing patterns, adenocarcinoma $(\mathrm{CAC})(\mathrm{n}=10)$, and adenosquamous carcinoma (ASC) $(n=4)$. There were no HPV16-positive small cell neuroendocrine carcinomas in this population.

\section{HPV Testing Using L1 Consensus Primers}

Liquid-based cytologic samples were collected in PreservCyt $^{\circledR}$ (Hologic, Malborough, MA) at the time of clinical evaluation and the cellular DNA was extracted using the QIAamp ${ }^{\circledR}$ DNA Blood and Tissue Mini Kit (Qiagen, Valencia, CA). HPV genotyping was performed using the reverse line blot/Linear Array ${ }^{\circledR}$ HPV Genotyping Test (Roche Molecular Systems, Alameda, CA), as previously described [20].

\section{Variant Analysis}

Aliquots of cellular DNA from HPV16-positive tumor samples were analyzed for HPV16 E6 variant category using PCR amplification and bidirectional PCR-based fluorescent dideoxy chain termination sequencing using the same primers used for initial amplification, as previously described [11].

Sequence alignments were performed using CLUSTALW [23]. Only nucleotide changes verified as occurring on both strands were accepted.

An HPV16-variant category was assigned for each case using the prototype nucleotide sequence for HPV16 [24] (modified as HPV16R [25]) as well as published HPV16 E6 sequence patterns that define the different variants [3]. The 16-E category included the prototype sequence and related patterns showing only a small number of nucleotide changes, while the 16-NE categories included Asian-American (AA), Native-American (NA-1), and African (AF-1 and AF-2).

In the secondary analysis restricted to 16-E SCC cases, the variants were subdivided into 16-EP (prototype), 16EV (European prototype sequence with a small number of additional nucleotide differences), and 16-EV-G (European sequence with the common $350 \mathrm{~T}>\mathrm{G}$ substitution; cases with nucleotide changes in addition to $350 \mathrm{~T}>\mathrm{G}$ were also included).

\section{Statistics}

Tabular analyses were performed using chi square and Fisher's exact and Cochran-Mantel-Haenszel trend tests.
Statistical significance was assigned to 2 -sided probability values $<.05$.

\section{Acknowledgements}

This study was supported by grants from the Oklahoma Center for the Advancement of Science and Technology (OCAST HR05-136) and from the National Cancer Institute (03-A117523) as well as from contract N02-CP31102 from the National Cancer Institute. Drs. Wentzensen and Schiffman are supported by the Intramural Research Program of the National Institutes of Health. Special thanks are due to Greg Rydzak, Information Management Services, Silver Spring, MD for his assistance in data analysis as well as to Tracey Young and her associates in the Department of Obstetrics and Gynecology and Susan Nagelhout, CTR of the OU Medical Center Tumor Registry for their efforts in obtaining patient follow-up information.

\section{Author details}

${ }^{1}$ Department of Pathology, University of Oklahoma Health Sciences Center, 940 SL Young Blvd, Oklahoma City, Oklahoma, 73104-5042, USA. ${ }^{2}$ Department of Obstetrics and Gynecology, Division of Gynecologic Oncology, University of Oklahoma Health Sciences Center, 800 NE 10th St. Suite 2001-2, Oklahoma City, Oklahoma, 73104-5418, USA. ${ }^{3}$ Division of Cancer Epidemiology and Genetics, National Cancer Institute, 6120 Executive Blvd, Room 5024, Rockville, Maryland 20852-7234, USA. ${ }^{4}$ Department of Obstetrics and Gynecology, University of Missouri Health System, 115 Business Loop 70W, Columbia, Missouri 56203-3244, USA. ${ }^{5}$ Department of Pathology and Laboratory Medicine, Tulane University Health Sciences, 1430 Tulane Avenue SL-79, New Orleans, Louisiana 70112-2699, USA. ${ }^{6}$ Obstetrics and Gynecology Department, Vanderbilt University Medical Center, 1161 21st Ave S, Nashville, Tennessee 37232-0011, USA. 'Department of Cancer Etiology, City of Hope and the Beckman Institute, 1500 East Duarte Rd, Duarte, CA 91010-3012, USA.

\section{Authors' contributions}

REZ: overall leader for this effort including data generation, data analysis and writing of the manuscript; ET: performed chart reviews and patient followup; NW: current team leader for SUCCEED who contributed a subset of patients, participated in data interpretation and in writing of manuscript; CM: performed chart reviews and patient follow-up; RAA: technical supervisor responsible for laboratory analyses; RS: developed HPV16 variant methodology for this study; STD: oversaw genotyping and HPV16 variant methodology; MAG: contributed patients including SUCCEED patients for this study; SSW: original team leader for SUCCEED at NCl, contributed cases for this study; JW: contributed patients including SUCCEED cases; MS: original co-team leader for SUCCEED, contributed cases to this study, provided statistical analysis and data interpretation. All co-authors participated in the preparation of this manuscript and approved the final version.

\section{Competing interests}

The authors declare that they have no competing interests.

Received: 25 August 2011 Accepted: 28 October 2011 Published: 28 October 2011

\section{References}

1. Li N, Franceschi S, Howell-Jones R, Snijders PJ, Clifford GM: Human papillomavirus type distribution in 30,848 invasive cervical cancers worldwide: Variation by geographical region, histological type and year of publication. Int J Cancer 2010, 128:927-935

2. de Villiers E-M, Fauquet $\mathrm{C}$, Broker TR, Bernard $\mathrm{H}-\mathrm{U}$, zur Hausen $\mathrm{H}$ : Classification of papillomaviruses. Virology 2004, 324:17-27.

3. Yamada T, Wheeler C, Halpern A, Stewart A, Hildesheim A, Jenison S: Human papillomavirus type 16 variant lineages in United States populations characterized by nucleotide sequence analysis of the E6, L2, and L1 coding segments. J Virol 1995, 69:7743-7753.

4. Chan SY, Bernard HU, Ong CK, Chan SP, Hofmann B, Delius H: Phylogenetic analysis of 48 papillomavirus types and 28 subtypes and variants: a showcase for the molecular evolution of DNA viruses. J Virol 1992, 66:5714-5725. 
5. Hildesheim A, Schiffman M, Bromley C, Wacholder S, Herrero R, Rodriguez A, Bratti MC, Sherman ME, Scarpidis U, Lin QQ, Terai M, Bromley RL, Buetow K, Apple RJ, Burk RD: Human papillomavirus type 16 variants and risk of cervical cancer. J Natl Cancer Inst 2001, 93:315-318.

6. Xi LF, Koutsky LA, Hildesheim A, Galloway DA, Wheeler CM, Winer RL, Ho J, Kiviat NB: Risk for High-Grade Cervical Intraepithelial Neoplasia Associated with Variants of Human Papillomavirus Types 16 and 18. Cancer Epidemiol Biomarkers Prev 2007, 16:4-10.

7. Villa LL, Sichero L, Rahal P, Caballero O, Ferenczy A, Rohan T, Franco EL: Molecular variants of human papillomavirus types 16 and 18 preferentially associated with cervical neoplasia. J Gen Virol 2000, 81:2959-2968.

8. Berumen J, Ordonez RM, Lazcano E, Salmeron J, Galvan SC, Estrada RA, Yunes E, Garcia-Carranca A, Gonzalez-Lira G, Madrigal-de la Campa A: AsianAmerican Variants of Human Papillomavirus 16 and Risk for Cervical Cancer: a Case-Control Study. J Natl Cancer Inst 2001, 93:1325-1330.

9. Burk RD, Terai M, Gravitt PE, Brinton LA, Kurman RJ, Barnes WA, Greenberg MD, Hadjimichael OC, Fu L, McGowan L, Mortel R, Schwartz PE, Hildesheim A: Distribution of human papillomavirus types 16 and 18 variants in squamous cell carcinomas and adenocarcinomas of the cervix. Cancer Res 2003, 63:7215-7220.

10. Quint KD, de Koning MNC, van Doorn L-J, Quint WGV, Pirog EC: HPV genotyping and HPV16 variant analysis in glandular and squamous neoplastic lesions of the uterine cervix. Gynecol Oncol 2010, 117:297-301.

11. Zuna RE, Moore WE, Shanesmith RP, Dunn ST, Wang SS, Schiffman M, Blakey GL, Teel T: Association of HPV16 E6 variants with diagnostic severity in cervical cytology samples of 354 women in a US population. Int J Cancer 2009, 125:2609-2613.

12. Schiffman M, Rodriquez AC, Chen Z, Wacholder S, Herrero R, Hildesheim A, Desalle R, Befano B, Yu K, Safaeian M, Sherman ME, Morales J, Guillen D, Alfaro M, Hutchinson M, Solomon D, Castle PE, Burk RD: A PopulationBased Prospective Study of Carcinogenic Human Papillomavirus Variant Lineages, Viral Persistence, and Cervical Neoplasia. Cancer Res 2010, 70:3159-3169.

13. Zehbe I, Richard C, DeCarlo CA, Shai A, Lambert PF, Lichtig H, Tommasino M, Sherman L: Human papillomavirus 16 E6 variants differ in their dysregulation of human keratinocyte differentiation and apoptosis. Virology 2009, 383:69-77.

14. Takeda N, Sakuragi N, Takeda M, Okamoto K, Kuwabara M, Negishi H, Oikawa M, Yamamoto R, Yamada H, Fujimoto S: Multivariate analysis of histopathologic prognostic factors for invasive cervical cancer treated with radical hysterectomy and systematic retroperitoneal lymphadenectomy. Acta Obstet Gynecol Scand 2002, 81:1144-1151.

15. Macdonald OK, Chen J, Dodson M, Lee CM, Gaffney DK: Prognostic Significance of Histology and Positive Lymph Node Involvement Following Radical Hysterectomy in Carcinoma of the Cervix. Am J Clin Oncol 2009, 32:411-416.

16. Hacker N: Cervical Cancer. In Practical Gynecologic Oncology.. 4 edition. Edited by: Berek JS. Philadelphia PA: Lippincott Williams and Wilkins; 2005:337-395.

17. Look KY, Brunetto VL, Clarke-Pearson DL, Averette HE, Major FJ, Alvarez RD, Homesley HD, Zaino RJ: An Analysis of Cell Type in Patients with Surgically Staged Stage IB Carcinoma of the Cervix: A Gynecologic Oncology Group Study. Gynecol Oncol 1996, 63:304-311.

18. Im SS, Wilczynski SP, Burger RA, Monk BJ: Early Stage Cervical Cancers Containing Human Papillomavirus Type 18 DNA Have More Nodal Metastasis and Deeper Stromal Invasion. Clin Cancer Res 2003, 9:4145-4150.

19. Wang SS, Zuna RE, Wentzensen N, Dunn ST, Sherman ME, Gold MA Schiffman M, Wacholder S, Allen RA, Block I, Downing K, Jeronimo J, Carreon JD, Safaeian M, Brown D, Walker JL: Human Papillomavirus Cofactors by Disease Progression and Human Papillomavirus Types in the Study to Understand Cervical Cancer Early Endpoints and Determinants. Cancer Epidemiol Biomarkers Prev 2009, 18:113-120.

20. Zuna RE, Allen RA, Moore WE, Lu Y, Mattu R, Dunn ST: Distribution of HPV genotypes in 282 women with cervical lesions: evidence for three categories of intraepithelial lesions based on morphology and HPV type. Mod Pathol 2007, 20:167-174

21. Tavassoli FA, Devilee P, Ed: Pathology and Genetics of Tumors of the Breast and Female Genital Organs Lyon: IARC Press; 2003.
22. Wentz WB, Reagan JW: Survival in cervical cancer with respect to cell type. Cancer 1959, 12:384-388.

23. Thompson JD, Higgins DG, Gibson TJ: CLUSTAL W: improving the sensitivity of progressive multiple sequence alignment through sequence weighting, position-specific gap penalties and weight matrix choice. Nucl Acids Res 1994, 22:4673-4680.

24. Seedorf K, Krämmer G, Dürst M, Suhai S, Röwekamp WG: Human papillomavirus type 16 DNA sequence. Virology 1985, 145:181-185.

25. Myers G DH, Icenogle J, Bernard H-U, Baker A, Halpern A, Wheeler C: Human papillomaviruses: a compilation and analysis of nucleic acid and amino acid sequences Los Alamos, NM: Los Alamos National Laboratory; 1995.

doi:10.1186/1750-9378-6-19

Cite this article as: Zuna et al:: HPV16 variant lineage, clinical stage, and survival in women with invasive cervical cancer. Infectious Agents and Cancer 2011 6:19.

\section{Submit your next manuscript to BioMed Central and take full advantage of:}

- Convenient online submission

- Thorough peer review

- No space constraints or color figure charges

- Immediate publication on acceptance

- Inclusion in PubMed, CAS, Scopus and Google Scholar

- Research which is freely available for redistribution

Submit your manuscript at www.biomedcentral.com/submit
Ciomed Central 